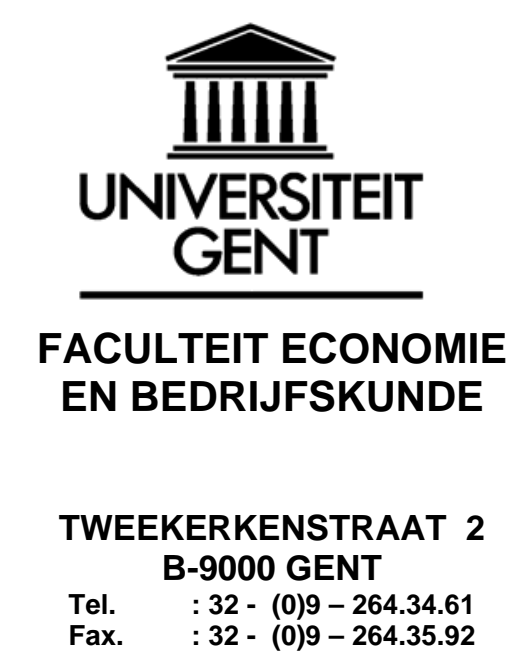

WORKING PAPER

\title{
Separating Financial From Commercial Customer Churn: A Modeling Step Towards Resolving The Conflict Between The Sales And Credit Department
}

\author{
Jonathan Burez ${ }^{1}$ \\ Dirk Van den Poel ${ }^{2}$
}

August 2007

$2007 / 476$

\footnotetext{
${ }^{1}$ Jonathan Burez, researcher, Department of Marketing, Ghent University.

${ }^{2}$ Corresponding author: Dirk Van den Poel, Professor of Marketing Modeling, Analytical Customer Relationship Management, Ghent University, Department of Marketing, Tweekerkenstraat 2, B-9000 Gent, Belgium. Phone: +32 926489 80, Fax: +32 9264 42 79, Email: dirk.vandenpoel@UGent.be
}

For more papers about analytical CRM, please visit: $\underline{w w w . c r m . U G e n t . b e ~ o r ~}$ www.datamining.UGent.be 


\title{
Separating financial from commercial customer churn:
}

\section{A modeling step towards resolving the conflict between the sales and credit department.}

\author{
Jonathan Burez \& Dirk Van den Poel $^{3}$ \\ Ghent University, Faculty of Economics and Business Administration, Department of Marketing, \\ Tweekerkenstraat 2, B-9000 Gent, Belgium
}

\begin{abstract}
In subscription services, customers who leave the company can be divided into two groups: customers who do not renew their fixed-term contract at the end of that contract, and others who just stop paying during their contract to which they are legally bound. Those two separate processes are often modeled together in a so-called churnprediction model, but are actually two different processes. The first type of churn can be considered commercial churn, i.e., customers making a studied choice not to renew their subscriptions. The second phenomenon is defined as financial churn, people who stop paying because they can no longer afford the service. The so-called marketing dilemma arises, as conflicting interests exist between the sales and marketing department on the one hand, and the legal and credit department on the other hand.

This paper shows that the two different processes mentioned can be separated by using information from the internal database of the company and that previous bad-payment behavior is more important as a driver for financial than for commercial churn. Finally, it is shown on real-life data that one can more accurately predict financial churn than commercial churn (increasing within period as well as out-of-period prediction performance). Conversely, when trying to persuade customers to stay with the company, the impact of 'loyalty' actions is far greater with potential commercial churners as compared to financial churners. Evidence comes from a real-life field experiment.
\end{abstract}

Keywords: Customer Intelligence, analytical customer relationship management (aCRM), customer churn, attrition research, commercial churn, financial churn, credit risk, out-of-period validation

\footnotetext{
${ }^{3}$ Corresponding author: Prof. Dr. Dirk Van den Poel, Professor of Marketing, Tweekerkenstraat 2, B-9000 Gent, Belgium, Phone: +32 926489 80, Fax: +32 9264 42 79, E-mail: Dirk.VandenPoel@UGent.be,

Visit http://www.crm.UGent.be to obtain some more papers about Analytical CRM/Customer Intelligence
} 


\section{Introduction}

In this section, we first discuss the broad issue of conflicting interests of consumers, dealers and management, and within a company, of several departments (sales or marketing as opposed to credit and legal departments). The subject matter is introduced by a GM case study, followed by a description of subscription services.

\section{GM's Marketing Dilemma}

Among automakers, General Motors distinguished itself for its marketing techniques. GM led the field during the 1920s with their new focus on advertising, installment financing, and the art of styling low-priced automobiles (see e.g. Clarke, 1999). Sloan’s autobiography became a classic in business management: Sloan (1963) presented a narrative for the efficient organization and performance of GM as a model for the modern corporation.

Sloan's account was accurate, but also incomplete: it overlooked the tensions between dealers and managers born out of the particular details in marketing automobiles - details that added up to what Clarke (2003) calls consumers' marketing dilemma. It was not just that management addressed the question of profitability in terms of efficiency - as consumers' design choices proliferated, for instance, GM faced a more complex job in producing vehicles; or inaccuracies in coordinating the production of cars with dealers' orders or consumers' demands resulted in unwanted cars (and costs) that either dealers or GM shouldered - but they also focused on profits in terms of market transactions - how dealers worked with the factory in ordering cars, and how they negotiated with consumers in selling cars. The three parties - consumers, dealers, and management - faced tension to the extent that one party's profit came at the expense of another party.

\section{Subscription Services}

Part of that same dilemma exists in the world of pay tv. Premium (cable) television content is a classic example of subscription services: you have the basic service (package of channels) with a few extra options. Pay-tv companies sell their service to customers typically via contracts with a fixed term ${ }^{4}$. The actual (initial) selling is done trough retailers. From the moment a customer signs a contract, every contact (for invoices, complaints, renewal, contract termination...) goes via the company itself.

The reminder of this study is organized as follows. In a literature review, we will first discuss behavioral loyalty and customer relationship management (CRM) in subscription services, and then return to the marketing dilemma faced in subscription services. Subsequently, we will build a case about, and hypothesize on churn definitions, variable importance, and the impact of marketing interventions. After a methodological part, the case study at the pay-TV company is described, and results are reported. These are used to analyze a field experiment, followed by conclusions, and directions for further research.

\footnotetext{
${ }^{4}$ We consider pay per view as a separate product.
} 


\section{Literature}

\section{Behavioral Loyalty and CRM}

Broadly speaking, a subscription renewal decision is a type of repeat buying. Dick and Basu (1994, p. 99) state that “customer loyalty is viewed as the strength of the relationship between an individual's relative attitude and his/her repeat patronage”. In a contractual setting and more specifically in subscription services, the behavioral loyalty measure is the renewal decision: does a customer renew his/her fixed term contract with the company.

Kumar and Ramani (2004) viewed customer relationship management (CRM) as the process of achieving and maintaining an ongoing relationship with customers across multiple customer touch points through differential and tailored treatment of individual customers based on their likely responses to alternative marketing programs, such that the contribution of each customer to the overall profitability of the firm is maximized. CRM in subscription services comes down to "attracting new customers”, what Ryals (2005) calls offensive marketing, and "keeping the existing customers”, known as defensive marketing (Ryals, 2005).

The importance of retaining customers should not be overlooked, as emphasized in articles published by Reichheld and Sasser (1990). Reinartz, Thomas and Kumar (2004) show that insufficient allocation to customer-retention efforts will have a greater impact on long-term customer profitability as compared to insufficient allocation to customer-acquisition efforts.

\section{Marketing Dilemma at a Pay TV Company}

For both offensive and defensive marketing in subscription services, the marketing dilemma as first described by Clarke (2003) manifests itself within the service provider. With regard to attracting new customers, retailers are motivated to sell as many new subscriptions as possible, as they are rewarded per subscription sold. Whether the customer is creditworthy or not, does not really bother them when selling a contract. But of course, both the legal department - that deals with illegal termination of a contract - and the credit department - that deals with arrears are the victim of this overzealous selling. The credit department suffers because outstanding debts are a burden to the company. The legal department gets an overload of work, if customers terminate their contract midway their contractual term. Considering retaining the existing customer base, the marketing department tries to convince as many customers to renew their contract as possible. This can be done proactively and reactively. Reactively is the standard procedure. A customer who did not renew his or her contract is contacted in an attempt to convince him/her to do so anyway. Proactive targeting of defection-prone customers can be done using a churn-prediction model. But here again, the marketing dilemma emerges. As mentioned before the credit and the legal department only want creditworthy customers to renew contracts, whereas the sales department wants every existing customer to renew. Moreover, as proactive targeting is rather expensive, a company does not want to spend money on a customer who would renew anyway. On the contrary, it wants to convince those customers who can afford the service, but are not entirely sure they need the service.

\section{Churn Definitions}

In order to proactively target those customers who do not face financial distress, but are no longer absolutely convinced of the service itself, we redefine our churn definitions. Customers who died or moved abroad during the 
period of investigation are left out of the investigation in any case. This involuntary churn is detectable, but not predictable and absolutely not actionable marketing wise. Within the group of churners, a further distinction should be made between those customers who can no longer afford the service, and those who cancel the service because they do no longer want it. In the internal database of the service provider, we find no information on the reason why a customer defected; only about the way (and time) a customer terminated his/her contract. We hypothesize this is a good proxy for the difference between financial and commercial churn.

$\mathrm{H}_{1}$ : Based on the way a customer terminates a contract - which we find in the internal database of the service provider - we will show that there exist three different types of churn: involuntary churn, financial churn and commercial churn.

\section{Variable Importance}

Occam's Razor, long admired, is usually interpreted to mean that simpler is better. Unfortunately, in prediction, accuracy and simplicity (interpretability) are in conflict (Breiman, 2001a, 2001b). When using Random Forests (Breiman, 2001 - see Methodology Section) as classification algorithm, no 'sign' information nor parameter estimate is returned for each of the independent variables. It does, however, provide a very good and unbiased importance measure. We will therefore only formulate hypotheses on the importance of some variables.

As this study focuses on the difference between customers defaulting their contracts, and customers deliberately terminating their contracts, we also include variables often used in credit scoring, but not (often) used in churn prediction. Predictor variables commonly used in credit scoring studies include various debt-ratio and other cash flow-oriented surrogates, employment time, home ownership, major credit card ownership, and representations of past payment history (e.g., Overstreet et al., 1992). Additional variables that can be added to the model include detailed credit bureau reports (e.g., Overstreet and Bradley, 1994) which give a better view on bad-payment behavior of a customer with other companies as well. Thomas (2000) compares credit-scoring systems to behavioral scoring systems, which allow lenders to make better decisions in managing existing clients by forecasting their future performance. The extra information is the repayment and ordering history of this customer. Desai et al. (1996) use credit bureau reports and the number of delinquent accounts over the last 12 months.

Somol et al. (2005) and Baesens et al. (2003) name credit history as one of the most important variables for classification of credit scoring in the German credit data set from the UCI repository. West (2000) uses two datasets, one of which is German credit data. Credit history emerges as the second most important variable when using both neural networks and mixture-of-experts networks. Piramuthu (1999, p. 259) states that "the past record of the borrower in meeting obligations is usually weighed heavily".

While the payment method itself is often used in churn prediction (e.g. Au et al, 2003), previous (bad) payment behavior is little used, and - to our knowledge - never mentioned as an important predictor. One study explicitly mentions the use of (bad) payment behavior: Yan, Wolniewicz and Dodier (2004) incorporate it in their customer behavior model, with which they attempt to prevent customer churn in telecommunications.

Mozer et al. (2000) state that the prediction of subscriber dissatisfaction should be used in combination with customer credit risk to decide on the retention campaign for that customer.

Drew et al. (2001) and Wei and Chiu (2002) do mention billing information as one of the sources for their churn model, but both studies do not mention bad-payment behavior specifically. Other studies did not include payment behavior at all: Au, Li and Ma (2003), Bhattacharya (1998), Bolton (1998), Weerahandi and Moitra (1995) to name a few. 
$\mathrm{H}_{2}$ : Previous bad-payment behavior is more important in the financial churn prediction model than in the commercial churn prediction model.

\section{Marketing Interventions}

It has been noted that different types of interventions can have different impacts on customers, depending on their customer characteristics (e.g., De Wulf et al. 2001). CRM interventions can have different purposes. For example, the CRM literature generally distinguishes between interventions with a call for action focusing on cross-selling and retention (i.e., direct mailings) and more relationship-oriented instruments (i.e., relationship magazines) (Berry 1995, Bhattacharya and Bolton 1999, McDonald 1998).

Convincing a customer in financial distress to stay is both pointless and ineffective. While there is a great possibility that you can convince them to renew their contract, you enlarge the chance that they will default on their contract. Therefore, we assume that targeting financial defection-prone customers worsens customer retention. Enhancing the relationship with potential commercial churners, however, might improve customer retention. In the latter case, targeting with relationship-oriented marketing interventions will hence improve customer retention.

$\mathrm{H}_{3}$ : Targeting financial defection-prone customers worsens customer retention, whereas targeting commercial defection-prone customers with relationship-oriented marketing interventions enhances customer retention.

\section{Methodology}

Attrition modeling has been the topic of interest of a lot of studies recently. In a first part of this methodology section, two modeling techniques will be discussed. In a second part, the split sample-design will be discussed in more detail.

\section{Modeling techniques}

Two notable types of attrition models can be distinguished based on the time window of observation (Van den Poel and Lariviere, 2003). Static attrition models investigate churn behavior at a specific moment in time, while dynamic attrition models observe a set of individuals over a period of time. Models that make it possible to estimate the risk or hazard rates, which change over time are preferred, because they produce more accurate forecasts than models that do not allow variables to take another value over time (Weerahandi and Moitra, 1995). In this study, both a static attrition model, using random forests, and a dynamic one, using survival analysis, are constructed. Both techniques are explained briefly in the following paragraphs.

\section{Random Forests}

In a binary classification context, Decision Trees (DT) became very popular because of their ease and interpretability (Duda et al., 2001). Moreover, DTs have the ability to handle covariates measured at different measurement levels. One major problem with DTs is their high instability (Hastie et al. 2001). A small change in the data often results in very different series of splits, which is often suboptimal when validating the trained model. In the past, this problem was extensively researched. 
It was Breiman (2001) who introduced a solution to the previously mentioned problem. The new classification technique is called: Random Forests. This technique uses a subset of $m$ randomly chosen predictors to grow each tree on a bootstrap sample of the training data. Typically, this number of selected variables - i.e. $m$ - is much lower than the total number of variables in the model. After a large number of trees is generated, each tree votes for the most popular class. By aggregating these votes over the different trees, each case is predicted a class label.

Random forests are already applied in several domains like bioinformatics, quantitative criminology, geology, pattern recognition, medicine, ... . However, the applications in marketing are rare (Buckinx and Van den Poel, 2005; Larivière and Van den Poel, 2005). Random Forests is used in this study for five reasons: (1) Luo et al. (2004) stated that the predictive performance is among the best of the available techniques. (2) The outcomes of the classifier are very robust to outliers and noise (Breiman, 2001). (3) This classifier outputs useful internal estimates of error, strength, correlation and variable importance (Breiman, 2001). (4) Reasonable computation time is observed by Buckinx and Van den Poel (2005). (5) Random forests are easy to implement because there are only two free parameters to be set, namely $m$, the number of randomly chosen predictors, and the total number of trees to be grown. We follow Breiman's (2001) suggestions: $m$ is set equal to the square root of the total number of variables - i.e. 13 because 171 explanatory variables are included in the model - and a large number of trees - in casu 300 - is chosen.

The Area Under the receiver operation Curve (AUC) is used as predictive performance indicator.

\section{Survival analysis}

Survival analysis is a class of statistical methods modeling the occurrence and timing of events (in casu: customer attrition) with the aim to establish descriptive or predictive models in which the risk of an event depends on covariates.

All of the standard approaches to survival analysis are probabilistic or stochastic. That is, the times at which the events occur are assumed to be realizations of some random process. It follows that $T$, the event time for some particular customer, is a random variable having a probability distribution.

Let us denote the probability density function (p.d.f.) of this variable by $f(t)$. The cumulative distribution function (c.d.f.) of variable $T$, denoted by $F(t)$. Hence,

$F(t)=\operatorname{Pr}\{T \leq t\}$.

For some individuals the time to failure may be observed completely, whereas for others we only have partial observation until some specific censoring time $c$. In survival analysis, it is common to work with a closely related function called the survivor function, defined as

$S(t)=\operatorname{Pr}\{T>t\}=1-F(t)$.

This leads to the following relationships:

$f(t)=\frac{d F(t)}{d t}=-\frac{d S(t)}{d t}$.

The hazard function is a central topic in the field of survival analysis and is defined as

$h(t)=\lim _{\Delta t \rightarrow 0} \frac{\operatorname{Pr}\{t \leq T<t+\Delta t \mid T \geq t\}}{\Delta t}$. 
The aim of the definition is to quantify the instantaneous risk that the event will occur at time $t$.

The Kaplan-Meier estimator (also known as the Product Limit Estimator) provides an estimate of the survival function from life-time data (Kaplan and Meier, 1958). In customer churn prediction, one measures the length of time customers remain with the company.

Let $S(t)$ be the probability that an item from a given population will have a lifetime exceeding $t$. For a sample from this population of size $N$ let the observed times until death of $N$ sample members be

$t_{1} \leq t_{2} \leq t_{3} \leq \ldots \leq t_{N}$

Corresponding to each $t_{i}$ is $n_{i}$, the number "at risk" just prior to time $t_{i}$, and $d_{i}$, the number of deaths at time $t_{i}$. The nonparametric maximum likelihood estimate of $S(t)$ is then a product of the form

$\hat{S}(t)=\prod_{t_{i}<t} \frac{n_{i}-d_{i}}{n_{i}}$.

When there is no censoring, $n_{i}$ is just the number of survivors just prior to time $t_{i}$. With censoring, $n_{i}$ is the number of survivors less the number of losses (censored cases). It is only those surviving cases that are still being observed (have not yet been censored) that are "at risk" of an (observed) death.

\section{Split Sample Design}

For the static churn model, a split sample design was used (see Figure 1). 60 percent of the data is used for training the model, 40 percent for validating the model. Churn is modeled on the training set, and that model is applied on the validation set and an out-of-period sample to check it's lasting power.

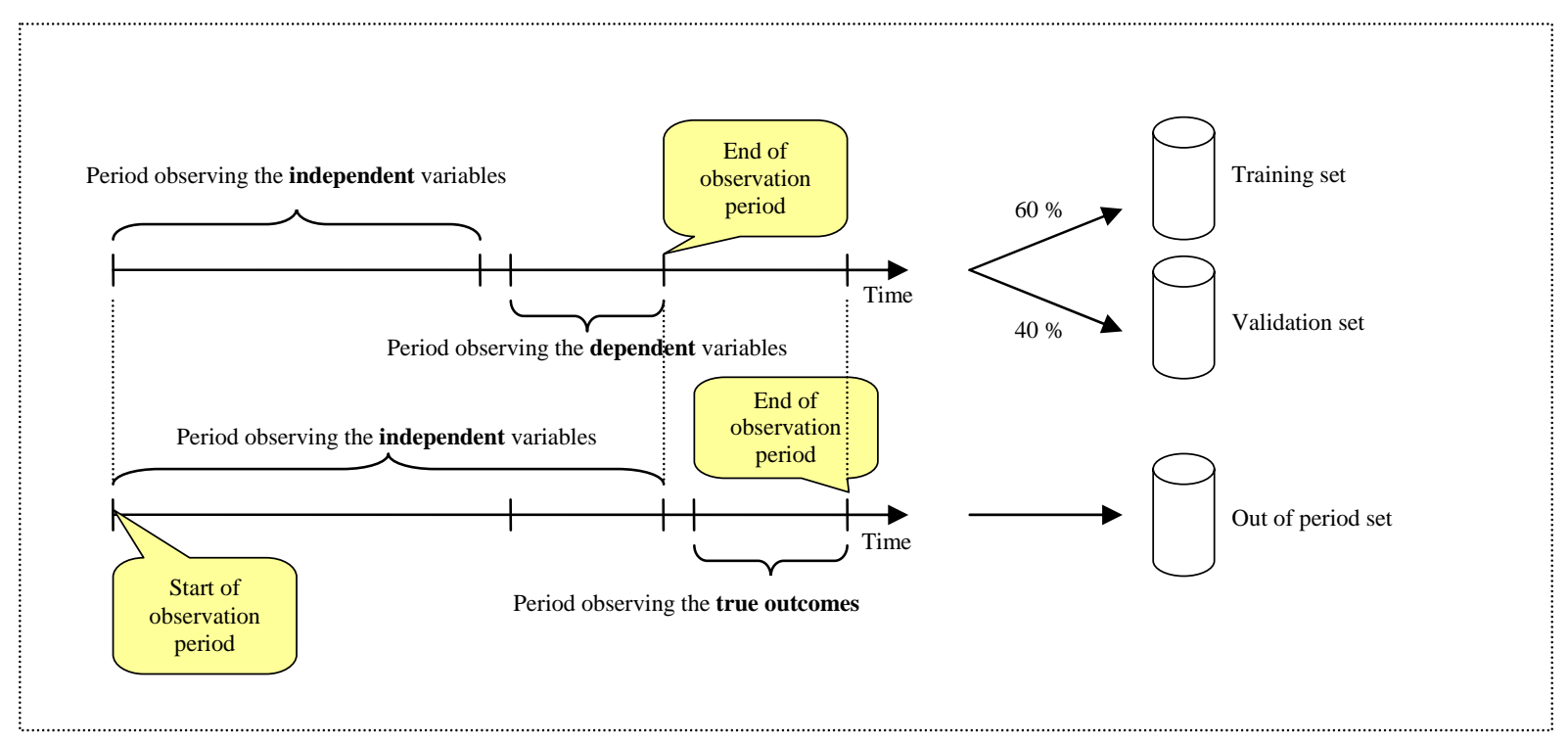

Figure 1: Graphical reflection of the time window used to build the static churn model

Three different types of independent variables will be modeled. They are defined later on. Furthermore, the impact on the churn prediction model of leaving some types of customers out of the training set will be investigated. This will become clear when defining the independent variables. 


\section{Case}

\section{Subscription services}

Pay TV is a subscription service requiring the customer to pay a fixed monthly contribution only; there is no extra per-minute-of-use charge (as is the case for instance in the mobile phone industry). Pay-per-view is considered as a separate branch of the market, and is not considered here. At this European pay-TV company, all customers have a 12-month subscription. Cancelling within that 12-month period is not allowed, nor is prematurely reporting that a subscription will not be renewed (customers have to report that they will not renew their subscription during the last month of the 12-month contract). If nothing is reported, the subscription is automatically renewed for a period of 12 months. While in theory thus not possible (because it is being refused by the company), in practice premature contract termination does occur a lot. In almost all cases, this is due to bad payment behavior: a customer cannot or does not want to pay his subscription any more, and therefore does no longer receive the broadcasting signal. The customer will have to pay the full amount on his contract though!

\section{Churn definitions}

A customer can have many reasons for cancelling a subscription: children moved out of the house, the service became too expensive, not satisfied with the offered broadcast, not happy with complaint handling... The optimal situation would be to know the reason why somebody cancels his/her subscription. And thus be able to identify those customers who cancelled because they do no longer want the service versus those who do want the service but have financial limits. This information is not known to the company. However, information in the database enables us to make a distinction between those customers who came at the end of their annual subscription, but did not renew. Customers have to send a cancellation letter to do so. Not renewing is then a well thought through decision. Those customers are considered commercial churners. Secondly, you have those customers who stopped paying during their subscription. The company doesn't really know why they stop: do they really have too little money, or do they just hope to dispose of their subscription. A third type of churn is a combination of both financial and commercial churn, called overall churn.

Two remarks should be made. First of all, there will be customers who come at the end of their subscription, and do not renew because of a lack of money. Or the other way around, there will be customers who stop paying halfway through a subscription, for other reasons than being short of money. Secondly, note that there are some special cases: people who die, or move to another country... Those customers are what we call involuntary churners, and are handled separately: they are either considered non-churners or are left out of the model (see further).

Because of these three churn definitions (financial, commercial and overall churn), three versions of both the survival and the random forests model are created: one for commercial, one for financial and one for overall churn.

\section{Churn Models}

The dynamic model (using survival analysis) takes into account all customers who started since 1995 and, right censors those customers still active in 2002. The static model (using random forests) considers all customers active on $28 / 2 / 2002$. The dependent variable is calculated on the subsequent year. 
As explained in the Split sample design Section, different subsets of the training set will be used while modeling churn. This is done to investigate the effects of leaving some customers out of the training set, on the predictive power of the model. E.g. when modeling financial churn, does one have to leave the commercial churners (who in this case are considered non churners) in the training set, yes or no? Will one be able to better capture the behavior of financial churners when commercial churners are incorporated in the data? Four subsets are created (see Figure 2):

1.

2.

3.

4.

$$
\begin{aligned}
& \text { All = all customers } \\
& \text { AC = active customers and commercial churners } \\
& \text { AF = active customers and financial churners } \\
& \text { ACF = active customers, commercial and financial churners }
\end{aligned}
$$

All: All customers

AC: Active customers and commercial churners

AF: Active customers and financial churners

ACF: Active customers, commercial and financial churners
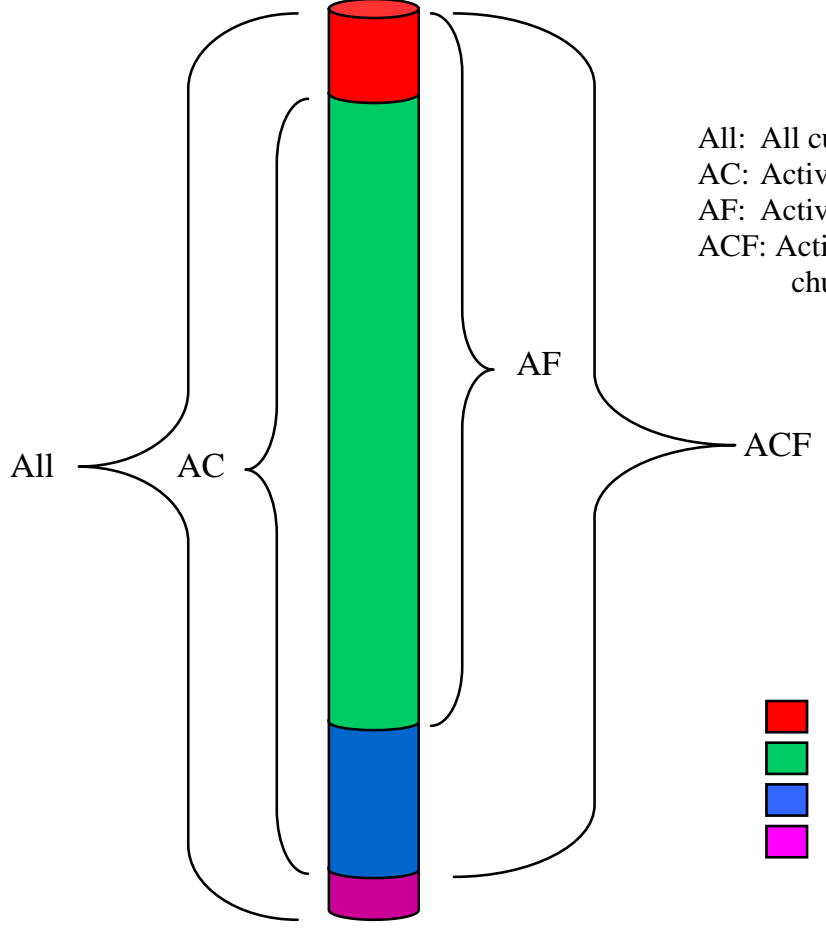

Financial churners

Active customers

Commercial churners

Involuntary churners

Figure 2: Subsetting the training set

\section{Data}

Data is extracted for this study from the data warehouse of the pay-TV company-a single integrated source of information combining data from all departments and services. It contains information about all customers that the pay-TV company has ever had. We used Oracle PL/SQL for data preparation and manipulation, and MATLAB and $\mathrm{R}$ to perform the statistical analyses.

For the dynamic model (using survival analysis), no explanatory variables are incorporated. All customers the service provider has ever had or still has were used (over 500,000). The static model had over 100,000 observations, of whom we collected 171 independent variables (Burez and Van den Poel, 2007). Those independent variables are listed in Appendix A and contain information about the current subscription (19 
variables), socio-demographic information (12), previous bad-payment behavior (14), history information (32) and contact information (94).

\section{Results}

\section{Survival Analysis}

The survival curve of the customers of the pay-TV company (see Figure 3) clearly confirms the subscription renewal process: after one year, a huge drop can be noticed in the survival curve. A lot of newly attracted customers take a one-year subscription and afterwards leave the company. After two years, a smaller number attrites...

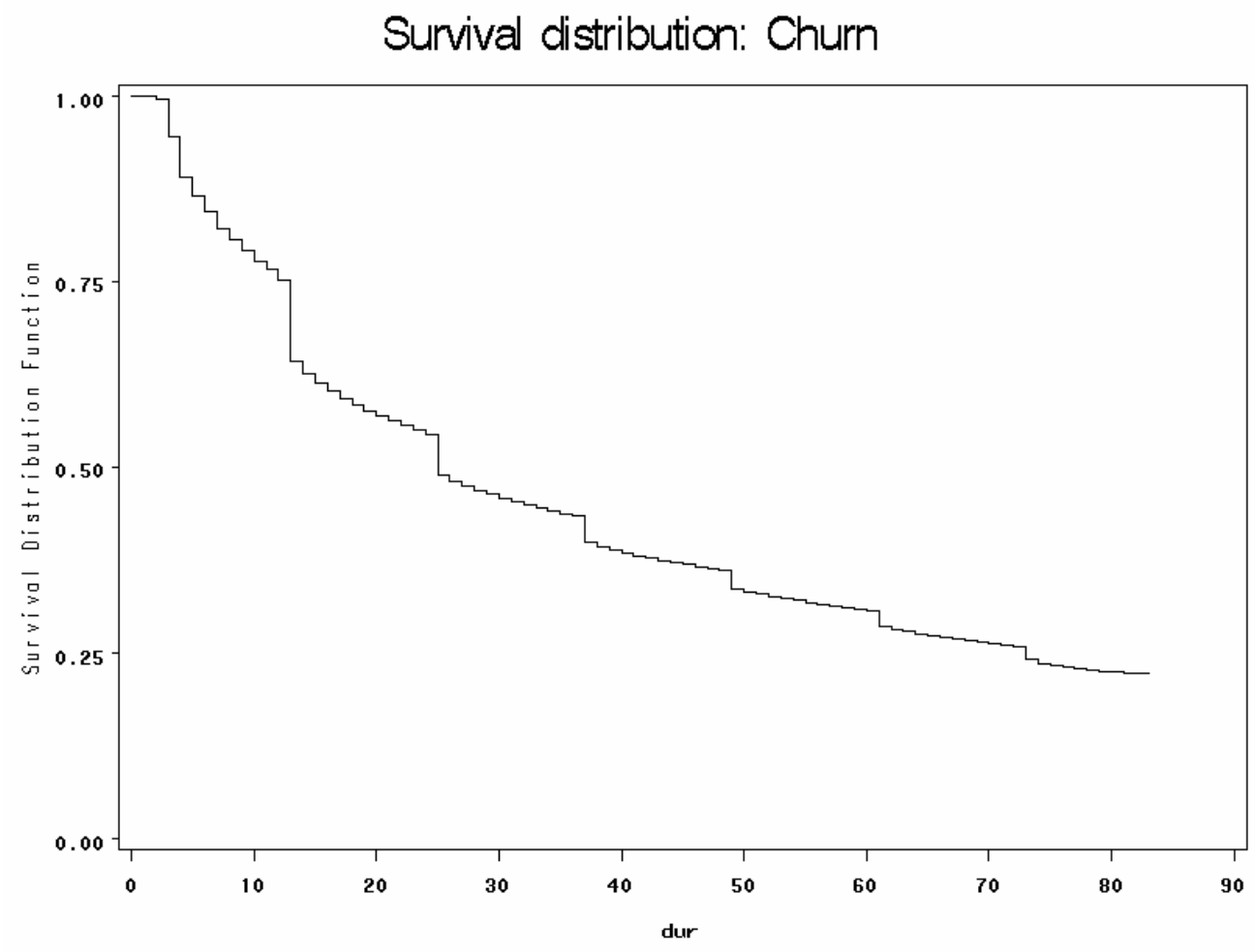

Figure 3: Survival distribution of overall churn

But another pattern emerges from the survival curve: those customers who stopped paying, for one reason or another, also represent a large proportion of churners. Especially in the first few years of the subscription, a lot of customers stop paying during a given subscription year, and thus stop receiving the signal.

Both phenomena together - churning after a year of subscription, and churning during the year - make that one out of three customers do not stay at the company more than one year, and more than one out of two customers leaves the company within two years.

The fact that there might be two different processes active was the reason to define three types of churn instead of just one (see Churn definitions). The survival curves for both commercial and financial churn are clearly different (see Figure 4). Commercial churners do not churn during their one-year subscription; they do it at the end of their 
subscription $^{5}$. The biggest part of commercial churn happens after one year of subscription: almost $20 \%$ of the customers leave at that point.
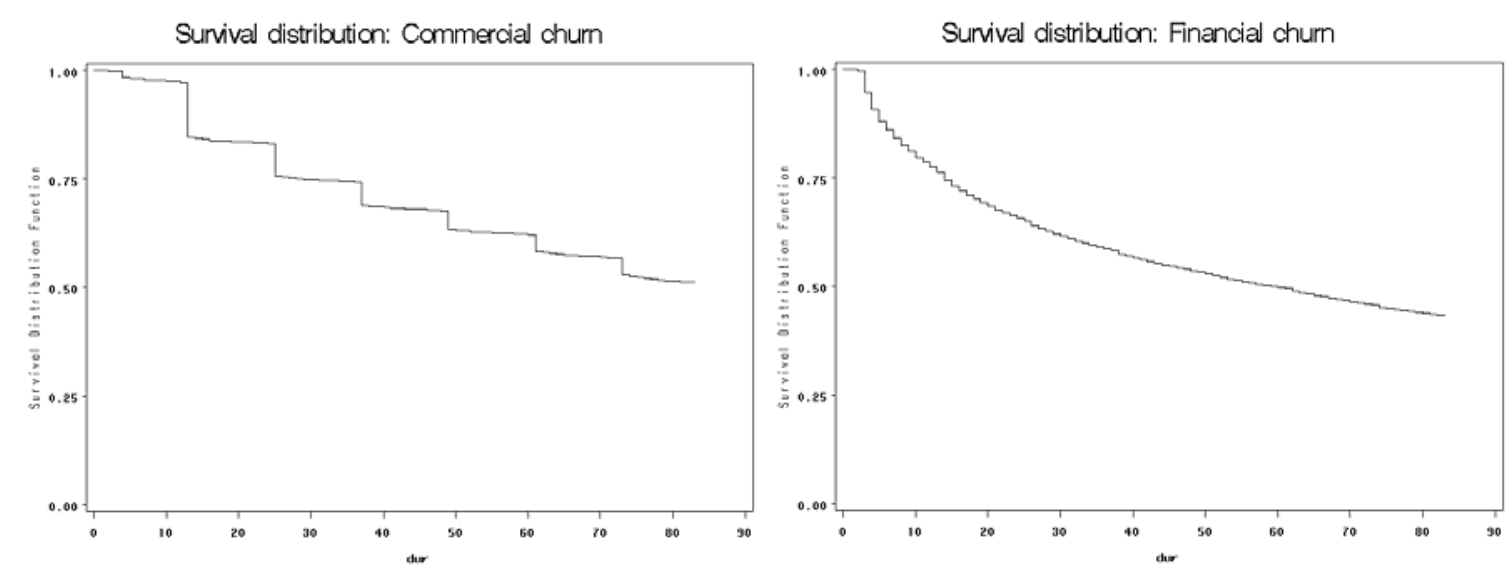

Figure 4: Survival distribution for commercial (left graph) and financial (right graph) churn

Financial churners leave at any point in their relationship with the company, in contrast to the yearly behavior for commercial churn. The curve decreases less and less, meaning that a customer is more at risk in the first few years of the subscription. The strange horizontal part of the curve in the first three months comes from the fact that customers have to pay a deposit plus more than two months subscription fees at the start of their first subscription. Hypothesis 1 is hereby confirmed, i.e., we are clearly able to visually distinguish the different types of churn behavior.

\section{Churn Prediction}

Now that we have shown that commercial and financial churn are two different processes, this information is used to make better churn predictions. From this point on, only the static models are used, and elaborated on.

The results of both the split sample design (training set, validation set and out-of-period sample), the subset creation within the training set, and the three churn definitions can be found in Table 1. In the left column, the dependent variable that is used for modeling is reported. Per dependent variable, the different subsets of the training set (as explained in Figure 2) are shown in the second column. Remember that All means that all observations in the training set are used when estimating a model, whereas $A C F$ leaves out the involuntary churners, $A C$ leaves out both involuntary and financial churners, and $A F$ leaves out both involuntary and commercial churners. The predictive performance of all those models is shown for both the validation set (column 3) and the out-of-period sample (column 4).

An example from Table 1 will make this clearer: $90.3 \%$ is the crossing of financial churn and ACF for the validation set. ACF means that involuntary churners were left out of the training set. Because the dependent variable is financial churn, the commercial churners - who are left in the training set in this example - have zero as value on the dependent variable. The estimated model is then applied on the validation set, which yields an AUC performance of $90.3 \%$.

\footnotetext{
${ }^{5}$ The horizontal parts are not perfectly horizontal because of individual exceptions.
} 


\begin{tabular}{|c|c|c|c|}
\hline $\begin{array}{l}\text { Dependent } \\
\text { variable } \\
\text { used in } \\
\text { the model }\end{array}$ & $\begin{array}{l}\text { Subset of the } \\
\text { training set } \\
\text { used for } \\
\text { estimating } \\
\text { the model }\end{array}$ & $\begin{array}{c}\text { Predictive } \\
\text { performance } \\
\text { on the } \\
\text { validation set }\end{array}$ & $\begin{array}{c}\text { Predictive } \\
\text { performance } \\
\text { on the } \\
\text { out-of-period } \\
\text { sample } \\
\end{array}$ \\
\hline \multirow{4}{*}{ 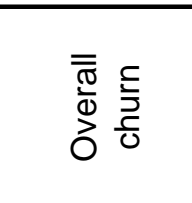 } & All & 80.5 & 74.6 \\
\hline & $A C$ & 69.4 & 61.1 \\
\hline & $\mathrm{AF}$ & 75.7 & 71.0 \\
\hline & $\mathrm{ACF}$ & 80.4 & 74.0 \\
\hline \multirow{3}{*}{ 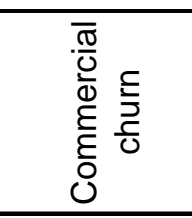 } & All & 75.7 & 68.6 \\
\hline & $A C$ & 74.3 & 67.9 \\
\hline & $\mathrm{ACF}$ & 75.7 & 68.6 \\
\hline \multirow{3}{*}{ 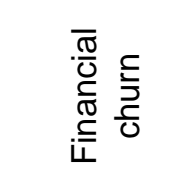 } & All & 90.4 & 86.0 \\
\hline & AF & 90.2 & 86.2 \\
\hline & $\mathrm{ACF}$ & 90.3 & 86.2 \\
\hline
\end{tabular}

Table 1: AUC performance results (shown in \%) from the different models: 3 different dependent variables, and 4 different subsets of the training set. Predictive performance is reported on both the validation set and on an out-of-period set.

The following conclusions can be drawn from this table:

1. Financial churn is a lot easier to predict than commercial churn (and hence than overall churn) because on average all financial churn models score about $86 \%$ on the out-of-period dataset compared to $68 \%$ for commercial churn models. Predicting financial churn leans towards credit scoring, which is known for its very high classification accuracy, and where previous (bad) payment behavior is classically the key predictor (Verstraeten \& Van den Poel, 2005).

2. There is no evidence that leaving the involuntary churners out of the training set influences predictive performance. Considering involuntary churners non-churners (i.e. keeping them in the training set, but with value zero on the dependent) yields similar performance for both financial and commercial churn.

3. Out-of-period forecasts are a lot more difficult than validation-set predictions since we observe a substantial drop-off between the predictive performance on the validation set (column 3) and the predictive performance on the out-of-period sample (column 4). It is thus very important to keep the models up to date. The performance of financial churn seems to be less affected than that of commercial churn, however.

It should be noted that any combination of both a financial and a commercial churn model does not come up with improved predictions for overall churn compared to the overall churn model itself.

\section{Variable Importance}

A nice feature of Random Forests is that it returns variable importance, by using internal out-of-bag estimates. For the financial churn prediction model, 136 variables are significant out of 171, for the commercial churn prediction model, 143 variables are significant (see Appendices B and C for the variable importance of all variables). 
Table 2 shows the most important variables for the financial churn prediction model. The last three columns represent respectively the z-value, the ranking, and the significance. For those variables, we also include in columns 2-5 the importance of those variables in the commercial churn prediction model.

The table clearly shows that we can confirm hypothesis 2. Variables like canc_99P, nbr_canc, canc_78P and rap_rec, all variables describing the previous bad-payment behavior of a customer, are far more important in the financial compared to the commercial churn prediction model.

\begin{tabular}{|c|c|c|c|c|c|c|}
\hline \multirow{3}{*}{$\begin{array}{c}\text { Variable } \\
\text { Name }\end{array}$} & \multicolumn{3}{|c|}{ Commercial Churn } & \multicolumn{3}{|c|}{ Financial Churn } \\
\hline & \multicolumn{3}{|c|}{ Importance } & \multicolumn{3}{|c|}{ Importance } \\
\hline & Z score & ranking & $\mathbf{p}$ & Z score & ranking & p \\
\hline canc_99P & 28,443 & 6 & 0 & 52,275 & 1 & 0 \\
\hline nbr_canc & 16,232 & 29 & 0 & 52,046 & 2 & 0 \\
\hline length_subs & 31,786 & 4 & 0 & 32,944 & 3 & 0 \\
\hline lor & 29,396 & 5 & 0 & 31,135 & 4 & 0 \\
\hline noc2 & 26,218 & 7 & 0 & 29,33 & 5 & 0 \\
\hline monetary & 25,968 & 8 & 0 & 29,294 & 6 & 0 \\
\hline tel_fix & 12,14 & 50 & 0 & 26,722 & 7 & 0 \\
\hline nov2 & 23,86 & 10 & 0 & 26,457 & 8 & 0 \\
\hline canc_78P & 7,875 & 74 & 0 & 25,438 & 9 & 0 \\
\hline rec_og & 38,233 & 2 & 0 & 23,967 & 10 & 0 \\
\hline og_3 & 22,042 & 12 & 0 & 22,054 & 11 & 0 \\
\hline cash_free & 20,817 & 15 & 0 & 19,613 & 12 & 0 \\
\hline call_positive & 14,008 & 38 & 0 & 18,406 & 13 & 0 \\
\hline no_renew & 17,431 & 22 & 0 & 18,277 & 14 & 0 \\
\hline at_ttcmens & 14,306 & 36 & 0 & 18,228 & 15 & 0 \\
\hline rap_rec & 13,197 & 43 & 0 & 17,817 & 16 & 0 \\
\hline in_call_A & 17,487 & 21 & 0 & 17,525 & 17 & 0 \\
\hline rap_amount_c & 24,908 & 9 & 0 & 17,212 & 18 & 0 \\
\hline markov2 & 17,325 & 23 & 0 & 17,149 & 19 & 0 \\
\hline og_19 & 15,981 & 30 & 0 & 15,868 & 20 & 0 \\
\hline
\end{tabular}

Table 2: Variable Importance for Financial versus Commercial Churn

\section{Churn Prevention: A Field Experiment}

A large-scale field experiment was conducted to test the influence of three customer retention actions on relational behavior: free movie tickets, an invitation to a unique event, and a satisfaction questionnaire. All Pay-TV customers who had to renew their subscription in December 2003, and of whom the company had a telephone number, were candidates for one of the actions. 24,185 customers satisfied this condition. We selected 7,350 customers with the highest churn probability (labeled top 30\%).

Those customers were divided into four groups via systematic sampling (Churchill and Iacobucci, 2002, p.484): One group of 1,050 customers would receive two free movie tickets, a second group of 2,100 customers would receive an invitation for two to a unique event, a third group of 2,100 customers was asked to respond to a satisfaction questionnaire by telephone; the fourth group (2,100 customers) served as a control group.

The questionnaire was conducted by telephone by a specialized firm, two and a half months before the moment in time at which customers had to renew their subscription (October 17, 2003). The interviewer requested 
participation from the "person in your household who was the main promoter of subscribing to Pay-TV". The survey took about 7 minutes to complete on average, and inquired into a number of motivations, usage and satisfaction questions eliciting respondents' evaluation of specific features (e.g. price, programming, movies broadcasted, sports programs...) followed by the general question, "Overall, how satisfied are you with the PayTV company?”

The results of the field experiment itself are described in Burez and Van den Poel (2007).

\begin{tabular}{cccccc} 
& & \multicolumn{4}{c}{ Relationship Marketing Interventions } \\
\cline { 3 - 6 } Dependent & Predicted & Control & & Telephonic & \\
\cline { 3 - 6 } variable & probability & group & & Avant-premion & Movie \\
questionnaire & tickets \\
\hline \hline \multirow{2}{*}{$\begin{array}{c}\text { Commercial } \\
\text { churn }\end{array}$} & All & 13.84 & 11.03 & 9.65 & 11.00 \\
& High & 18.23 & 13.99 & 11.27 & 12.95 \\
& Low & 6.50 & 6.62 & 6.79 & 7.52 \\
\hline \multirow{2}{*}{ Financial } & All & 3.63 & 4.35 & 3.95 & 3.70 \\
churn & High & 4.13 & 4.73 & 5.11 & 4.15 \\
& Low & 3.10 & 3.93 & 2.70 & 3.28 \\
\hline Overall churn & & 17.99 & 15.86 & 14.00 & 15.00 \\
\hline \hline
\end{tabular}

Table 3: Results of the field experiment - a comparison between financial and commercial churn

While at the time of the field experiment, only an overall churn model was used, it can now be investigated whether a commercial and/or financial churn model would have improved customer retention. Table 3 gives the churn rates of the different groups, targeted with different relationship marketing interventions (RMIs). The leftmost column shows the dependent variable used for evaluation of the impact of the different RMIs. The second column indicates the predicted probability for the type of churn in column 1. E.g. for commercial churn, predicted probability high are those customers who were selected for the field experiment (because they were among the top $30 \%$ of the customers with the highest chance of overall churning) and are in the top $30 \%$ of the customers with the highest probability of commercial churning. Low customers were among the top 30\% with highest overall churning propensity, but not among the top 30\% with highest commercial churning chances. The same goes for financial churning. Note that for overall churn, because of the setup of the experiment, the predicted probability is high for all customers in the experiment.

Table 3 shows that the effect of all three actions was much higher on the at-risk commercial churners whereas the effect on the financial churners was opposite. Clearly the churn reduction was much bigger for commercial churn compared to overall churn. Financial churn could not be reduced; on the contrary, the churn rate slightly increased compared to the control group. These findings confirm our third hypothesis.

\section{Conclusion}

This paper investigated churn at a pay-TV company, using both static and dynamic churn prediction models. While the exact reasons for customer attrition are unknown, the way a customer ends a subscription turns out to be a good proxy for it. Based on this, two distinct types of churn were defined: commercial churn (not renewing a subscription) and financial churn (no longer paying invoices of a current subscription). Previous bad-payment behavior is far more important in financial churn prediction compared to commercial churn prediction. Financial churn prediction, which is similar to credit scoring, is easier to predict than commercial churn. 
While financial churn is easier to predict, commercial churn is much easier to prevent. A field experiment pointed out that you can convince commercially defection-prone customers to stay at your company, while this is not possible for financially defection-prone customers. This also diminishes the conflict between the sales and the credit department: instead of targeting all defection-prone customers, only the commercially defection-prone (and allegedly creditworthy) customers are now targeted. This may reduce the inherent conflict between those two departments. It is very important for marketers to know that different types of churn exist, and that they should be prevented with different actions.

\section{Directions for further research}

In this study, we differentiate between commercial and financial churn, based on the way a customer terminates his/her contract. We do so because this information is available in the internal database of the company. Questionnaire data could learn us more on the reasons for contract termination, and thus enable us to make a better distinction between customers who churn for financial reasons, and others.

A second opportunity for further research lays with the proportional hazards models. The estimation of the baseline hazard (as for example proposed by Dekimpe et al.) makes it possible for proportional hazards models to make individual churn predictions (e.g. in R). While thus theoretically possible, considering the large potential number of time-varying variables, it would take a lot of computation time and huge memory requirements to come up with the predictions. Hence it will be very hard to make this operational with current technology.

The a posteriori interpretation of the field experiment results with regard to financial and commercial churn should be handled carefully. The setup of a new field experiment, with a selection based on a commercial churn prediction model is to confirm our results. Further research could inquire into the cost-effectiveness of different incentives for different types of churn.

\section{Acknowledgements}

We are indebted to the late Professor Leo Breiman for making available the fortran code of his Random Forests method. Moreover, this research is supported by the IAP research network grant number P6/03 of the Belgian government (Belgian Science Policy). 


\section{References}

Allison, P.D. (1995). Survival Analysis Using The SAS System, SAS Institute Inc., North Carolina.

Au, T., Li, S. and Ma, G. (2003). Applying and Evaluating Models to Predict Customer Attrition Using Data Mining Techniques. Journal of Comparative International Management, 6 (1).

Au, W., Chan, K.C.C. and Yao, X. (2003). A Novel Evolutionary Data Mining Algorithm With Applications to Churn Prediction. IEEE Transactions On Evolutionary Computation,7 (6), 532-545.

Baesens, B., Van Gestel, T., Viaene, S., Stepanova, M., Suykens, J. and Vanthienen, J. (2003). Benchmarking state-of-the-art classification algorithms for credit scoring. Journal of the Operational Research Society, 54(5): 627-35.

Berry, L.L. (1995). Relationship marketing of services - growing interest, emerging perspectives. Journal of the Academy of Marketing Science, 23 (4), 236-45.

Bhattacharya, C.B. (1998). When Customers Are Members: Customer Retention in Paid Membership Contexts. Journal of the Academy of Marketing Science, 26 (1), 31-44.

Bhattacharya, C. B. and Bolton, R.N. (1999). Relationship marketing in mass markets. Sheth, J.N. and Parvatiyar, A., eds. Handbook of Relationship Marketing. Sage Publications, Thousand Oaks, CA, 327-354.

Bolton, R.N. (1998). A Dynamic Model of the Duration of the Customer's Relationship with a Continuous Service Provider: The Role of Satisfaction. Marketing Science, 17 (1), 45-65.

Breiman, L. (2001) Statistical Modeling: The Two Cultures. Statistical Science, 16 (3), 199-231.

Breiman, L. (2001) Random Forests. Machine Learning Journal, 45, 5-32.

Brill, J. (1998). The importance of credit scoring models in improving cash flow and collections. Business Credit, 100(1), 16-17.

Buckinx, W. and Van den Poel, D. (2005). Customer base analysis: partial defection of behaviourally loyal clients in a non-contractual FMCG retail setting. European Journal Of Operational Research, 164 (1), 252-268.

Burez, J. and Van den Poel, D. (2007). CRM at a pay-TV company: Using analytical models to reduce customer attrition by targeted marketing for subscription services. Expert Systems with Applications, 32 (2), 277-288.

Churchill, G. A., Jr., \& Iacobucci, D. (2002). Marketing research methodological foundations (8th ed.). Mason, Ohio: South-Western Thompson Learning.

Clarke, S. (1999). Managing Design: The Art and Colour Section at General Motors, 1927-1941. Journal of Design History, 12, 65-79.

Clarke, S. (2003). Closing the Deal: GM's Marketing Dilemma and its Franchised Dealers, 1921-41. Business History, 45 (1), 60-79.

Cox, D.R. \& Snell E.J. (1989). Analysis of Binary Data, 2nd Edition, Chapman and Hall, London.

Dekimpe, M., Van de Gucht, L., Hanssens, D. \& Powers, K. (1998). Long-Run Abstinence After Narcotics Abuse: What Are the Odds? Management Science, 44(11), 1478-1492.

Desai, V.S., Crook, J.N. and Overstreet, G.A.Jr. (1996). A comparison of neural networks and linear scoring models in the credit union environment. European Journal of Operational Research, 95, 24-37.

De Wulf, K., Odekerken-Schröder, G., Iacobucci, D. (2001). Investments in consumer relationships: a crosscountry and cross-industry exploration. Journal of Marketing, 65 (4), 33-50. 
Dick, A. S. and Basu, K. (1994). Customer Loyalty: Toward an Integrated Conceptual Framework. Journal of the Academy of Marketing Science, 22 (2), 99-113.

Drew, J.H., Mani, D.R., Betz, A.L., and Datta, P. (2001). Targeting Customers with Statistical and Data-Mining Techniques. Journal of Service Research, 3 (3), 205 - 219.

Duda R. O., Hart, P.E. and Stork, D.G. (2001). Pattern classification. Wiley, New York.

Hastie, T., Tibshirani, R. and Friedman, J. (2001). The elements of statistical learning: data mining, inference and prediction. Springer-Verlag.

Kaplan, E.L. \& Meier, P. (1958). Nonparametric estimation from incomplete observations. Journal of the American Statistical Association, 53, 457-481.

Kumar, V. and Ramani, G. (2004). Taking Customer Lifetime Value Analysis to the Next Level. Journal of Integrated Communications, 27-33.

Larivière B. and Van den Poel D. (2005). Predicting customer retention and profitability by using random forests and regression forests techniques. Expert Systems With Applications, 29 (2), 472-484.

Lucas, A. (2001). Statistical challenges in credit card issuing. Applied Stochastic Models in Business and Industry, 17(1), 83-92.

Luo, T., Kramer K., Goldgof, D.B., Hall, L.O., Samson, S., Remsen, A. and Hopkins, T. (2004). Recognizing plankton images from the shadow image particle profiling evaluation recorder. IEEE Transactions on Systems Man and Cybernetics Part B - Cybernetics, 34 (4), 1753-1762.

Magee, L. (1990). R2 measures based on Wald and likelihood ratio joint significance tests. American Statistician, 44, 250-253.

McDonald, William J. (1998). Direct Marketing: An Integrated Approach. Irwin/McGraw-Hill, Boston, MA.

Mozer, M.C., Wolniewicz, R., Grimes, D.B., Johnson, E. and Kaushansky, H. (2000). Predicting Subscriber Dissatisfaction and Improving Retention in the Wireless Telecommunications Industry. IEEE Trans. Neural Networks, 11 (3), 690-696.

Overstreet, Jr., G.A., and Bradley, Jr., E.L. (1994). Applicability of generic linear scoring models in the USA Credit Union environment: Further analysis, Working Paper. University of Virginia.

Overstreet, Jr., G.A., Bradley, Jr., E.L., and Kemp, R.S. (1992). The flat-maximum effect and generic linear scoring model: A test. IMA Journal of Mathematics Applied in Business and Industry 4, 97-109.

Piramuthu, S. (1999). Financial credit-risk evaluation with neural and neurofuzzy systems. European Journal of Operational Research, 112 (2), 310-321.

Reichheld, F. and Sasser, W. (1990). Zero defects: quality comes to services. Harvard Business Review, 68 (5), 105-111.

Reinartz, W., Thomas, J. and Kumar, V. (2005). Balancing Acquisition and Retention Resources to Maximize Profitability. Journal of Marketing, 69 (1), 63-79.

Ryals, L. (2005). Making Customer Relationship Management Work: The Measurement and Profitable Management of Customer Relationships. Journal of Marketing, 69 (4), 252-261.

Sloan, Alfred P. Jr. (1963), My Years with General Motors. DoubleDay.

Somol, P., Baessens, B., Pudil, P. and Vanthienen, J. (2005) Filter- versus Wrapper-based Feature Selection for Credit Scoring. International Journal of Intelligent Systems, 20, 985-999. 
Therneau, T.M. \& Grambsch, P.M. (2000). Modeling Survival Data: Extending the Cox Model, Springer, New York.

Thomas, L.C. (2000). A survey of credit and behavioural scoring: forecasting financial risk of lending to consumers. Internation Journal of Forecasting, 16(2), 149-172.

Thomas, L.C., Oliver, R.W. \& Hand D.J. (2005). A survey of the issues in consumer credit modeling research. Journal of the Operational Research Society, 56 (9). 1006-1015.

Van den Poel, D. \& Lariviere B. (2004). Customer Attrition Analysis for Financial Services Using Proportional Hazard Models. European Journal of Operational Research, 157(1), 196-217.

Venkatesan, R. \& Kumar V. (2004). A customer lifetime value framework for customer selection and resource allocation strategy. Journal of Marketing. 68(4): 106-125.

Verstraeten, G. \& Van den Poel, D. (2005). The impact of sample bias on consumer credit scoring performance and profitability. Journal of the operational research society. 56(8): 981-992.

Weerahandi, S. \& Moitra, S., (1995). Using survey data to predict adoption and switching for services, Journal of Marketing Research, 32(1), 85-96.

Wei, C.P. and Chiu, I.T. (2002). Tuning telecommunications call detail to churn prediction: A data mining approach. Expert Systems with Applications, 23 (2), 103-112.

West, D. (2000). Neural network credit scoring models. Computers \& Operations Research, 27, 1131-1152.

Yan, L., Wolniewicz, R. H., and Dodier, R. (2004). Predicting Customer Behavior in Telecommunications. IEEE Intelligent Systems, 19 (2), 50-58. 


\section{Appendix A}

\section{List of variables in the static churn prediction model}

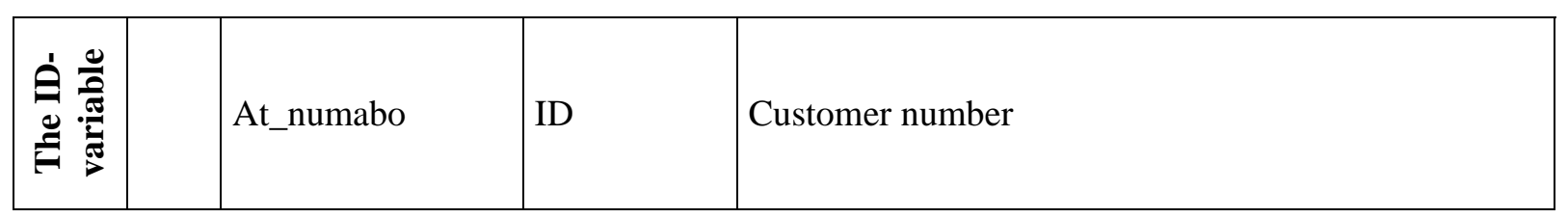

\begin{tabular}{|c|c|c|c|}
\hline 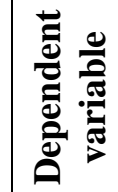 & Churn & Binary & $\begin{array}{l}\text { Whether the customer churned between 28/2/2002 } \\
\text { and } 28 / 2 / 2003\end{array}$ \\
\hline
\end{tabular}

\begin{tabular}{|c|c|c|c|c|}
\hline \multirow{19}{*}{ 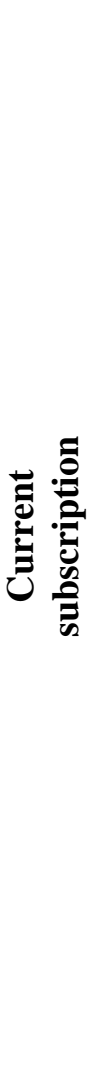 } & 1. & At_ttcmens & Continuous & Monthly payment of the current subscription \\
\hline & 2. & At_duree & Continuous & Length in months of the current subscription \\
\hline & 3. & Product1 & Binary & \multirow{2}{*}{$\begin{array}{l}\text { Type of product the customer has now: } \\
\text { product } 1=1 \rightarrow \text { basic service of the pay-TV } \\
\text { company only, product } 2=1 \rightarrow \text { premium } \\
\text { channels only, both }=1 \rightarrow \text { basic service as } \\
\text { well as premium channels }\end{array}$} \\
\hline & 4. & Product2 & Binary & \\
\hline & 5. & Tech & Binary & The technology used: $0=$ analog, $1=$ digital \\
\hline & 6. & Nbr_products & Continuous & $\begin{array}{l}\text { Number of subscriptions the customer has on } \\
\text { 28/2/2002 (based on the linked numabo's) }\end{array}$ \\
\hline & 7. & Domi_monthly & Binary & $\begin{array}{l}\text { Does the customer pay monthly with direct debit? ( } 1 \\
=\text { yes, } 0=\text { no) }\end{array}$ \\
\hline & 8. & Exp_month_1 & Binary & \multirow{11}{*}{ Month in which the current subscription will expire. } \\
\hline & 9. & Exp_month_2 & Binary & \\
\hline & 10. & Exp_month_3 & Binary & \\
\hline & 11. & Exp_month_4 & Binary & \\
\hline & 12. & Exp_month_5 & Binary & \\
\hline & 13. & Exp_month_6 & Binary & \\
\hline & 14. & Exp_month_7 & Binary & \\
\hline & 15. & Exp_month_8 & Binary & \\
\hline & 16. & Exp_month_9 & Binary & \\
\hline & 17. & Exp_month_10 & Binary & \\
\hline & 18. & Exp_month_11 & Binary & \\
\hline & 19. & Opt & Binary & Does the customer have any options? $1=$ yes, $0=$ no \\
\hline
\end{tabular}




\begin{tabular}{|c|c|c|c|c|}
\hline \multirow{12}{*}{ 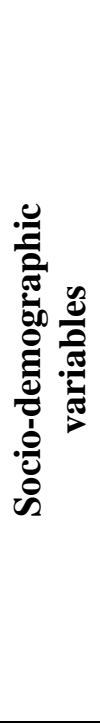 } & 20. & Ccivil & Binary & $\begin{array}{l}\text { Civil status of the customer ( } 0=\mathrm{Me}, \mathrm{Ml}, \mathrm{SM} ; 1= \\
\text { rest) }\end{array}$ \\
\hline & 21. & Age & Continuous & Age of the customer in years at start numabo \\
\hline & 22. & Age_mv & Binary & Is the date of birth missing? $1=$ yes, $0=$ no \\
\hline & 23. & Tel_mob & Binary & \multirow{2}{*}{$\begin{array}{l}\text { Do we have a telephone number of the customer } \\
\text { (tel_fix }=0 \text { and tel_mob }=0) \text { ? If yes, is it a fixed } \\
(\text { tel_fix }=1 \text { ) or a mobile }(\text { tel_mob }=1 \text { ) number? }\end{array}$} \\
\hline & 24. & Tel_fix & Binary & \\
\hline & 25. & Info_mv & Binary & $\begin{array}{l}\text { Is the information field filled in? } 1=\text { not filled in, } 0= \\
\text { filled in }\end{array}$ \\
\hline & 26. & Prov1 & Binary & \multirow{5}{*}{$\begin{array}{l}\text { Variables indicating what province the customer } \\
\text { comes from. If all }=0 \text {, then the customer lives in } \\
\text { Flanders or abroad. }\end{array}$} \\
\hline & 27. & Prov4 & Binary & \\
\hline & 28. & Prov5 & Binary & \\
\hline & 29. & Prov6 & Binary & \\
\hline & 30. & Prov7 & Binary & \\
\hline & 31. & Business & Binary & $\begin{array}{l}\text { Is the customer a company, based on the fields } \\
\text { information and name? } 1=\text { yes, } 0=\text { no }\end{array}$ \\
\hline
\end{tabular}

\begin{tabular}{|c|c|c|c|c|}
\hline \multirow{14}{*}{ 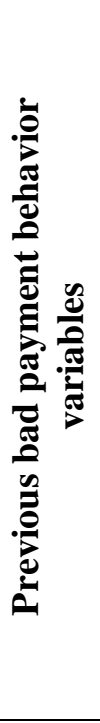 } & 32. & No_rappels & Continuous & Total number of reminders \\
\hline & 33. & No_cycles & Continuous & Number of cycles of bad payments \\
\hline & 34. & Rap_smooth & Continuous & Number of monthly newsletter (etat $=2$ ) \\
\hline & 35. & Rap_cut_adv & Continuous & Number of cutting advertisements (etat $=3$ or 4 ) \\
\hline & 36. & Rap_deactiv & Continuous & Number of deactivations of the decoder (etat $=5$ ) \\
\hline & 37. & Rap_to_pay & Continuous & Number of notices to pay (etat $=6$ ) \\
\hline & 38. & Rap_debt_rec & Continuous & Number of debt recoveries (etat $=7$ or 9 ) \\
\hline & 39. & Rap_not_recouvr & Continuous & Number of irrecoverable (etat $=8$ ) \\
\hline & 40. & Rap_outb & Continuous & Number of outbounds (etat $=10$ ) \\
\hline & 41. & Rap_amount & Continuous & Amount of all reminders \\
\hline & 42. & Rap_amount_c & Continuous & Amount of reminder times the number of cycle stage \\
\hline & 43. & Rap_proc_open & Binary & $\begin{array}{l}\text { Is there a reminder process running on } 28 / 2 / 2002 \text { ( } 1 \\
=\text { yes, } 0=\text { no) }\end{array}$ \\
\hline & 44. & Rap_rec & Continuous & Recency since last reminder \\
\hline & 45. & Rap_mv & Binary & $\begin{array}{l}\text { If there were any reminders in the past }(1=\text { no, } 0= \\
\text { yes) }\end{array}$ \\
\hline
\end{tabular}




\begin{tabular}{|c|c|c|c|c|}
\hline & 46. & Lor & Continuous & Length of relationship at $28 / 2 / 2002$ \\
\hline & 47. & Length_subs & Continuous & Length of actual subscriptions (lor - gaps) \\
\hline & 48. & Ind_subs & Continuous & Length_subs / lor \\
\hline & 49. & Markov & Continuous & $\begin{array}{l}\text { Markov value of the fourth order (no distinction is } \\
\text { made between analogue or digital) }\end{array}$ \\
\hline & 50. & Markov_dummy & Binary & $\begin{array}{l}\text { Indicating that there were less then } 50 \text { observations } \\
\text { for this Markov chain (Hence, Markov value of a } \\
\text { lower order is used) }\end{array}$ \\
\hline & 51. & Markov2 & Continuous & $\begin{array}{l}\text { Markov value of the third order (distinction between } \\
\text { analogue and digital) }\end{array}$ \\
\hline & 52. & Markov2_dummy & Continuous & $\begin{array}{l}\text { Indicating that there were less then } 50 \text { observations } \\
\text { for this Markov chain (Hence, Markov value of a } \\
\text { lower order is used) }\end{array}$ \\
\hline & 53. & Noc & Continuous & Absolute number of contracts \\
\hline & 54. & Noc2 & Continuous & Number of contracts relative to the lor (i.e. per year) \\
\hline & 55. & Nov & Continuous & Absolute number of versions of a contract \\
\hline & 56. & Nov2 & Continuous & Number of versions of a contract relative to the lor \\
\hline & 57. & Lc & Binary & $\begin{array}{l}\text { Are there } 2 \text { linked contracts for a customer, one for a } \\
\text { smartcard and one for a setup box? }\end{array}$ \\
\hline & 58. & Monetary & Continuous & The monetary value of the customer. \\
\hline & 59. & Dist_display & Binary & If a decoder was bought at ‘display’ distributor \\
\hline & 60. & Nbr_int & Continuous & $\begin{array}{l}\text { The number of times this customer has been without } \\
\text { subscription within a numabo or between linked } \\
\text { numabo's. }\end{array}$ \\
\hline 莲 & 61. & Cash_free & Continuous & $\begin{array}{l}\text { Summation of what the customer got for free in cash } \\
\text { over his lor. }\end{array}$ \\
\hline & 62. & Terme & Continuous & $\begin{array}{l}\text { Summation of what the customer got for free in } \\
\text { monthly terms over his lor. }\end{array}$ \\
\hline & 63. & Parrain & Binary & Does the customer have a godfather ( $1=$ yes, $0=$ no) \\
\hline & 64. & No_godchild & Continuous & $\begin{array}{l}\text { Of how many customers is this customer the } \\
\text { godfather? }\end{array}$ \\
\hline & 65. & Camp_c & Continuous & Was the customer recruited with a campaign? \\
\hline & 66. & Camp_d & Continuous & 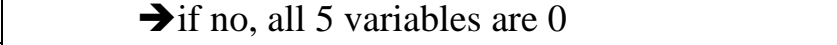 \\
\hline & 67. & Camp_e & Continuous & $\rightarrow$ if yes, one of the variables equals 1 , \\
\hline & 68. & Camp_p & Continuous & \\
\hline & 69. & Camp_x & Continuous & $\begin{array}{l}\mathrm{c}=\text { coupons, } \mathrm{d}=\text { distributor, } \mathrm{e}=\text { leaflet, } \mathrm{p}=\text { member-gets- } \\
\text { member, } \mathrm{x}=\text { else }\end{array}$ \\
\hline & 70. & Payeur & Continuous & Number of subscriptions this customer pays for. \\
\hline & 71. & Num_numabo & Continuous & $\begin{array}{l}\text { The number of linked numabo’s the customer has } \\
\text { (had) up to 28/2/2002 }\end{array}$ \\
\hline & 72. & Canc_78P & Continuous & Number of cancellations 'Annul ancien abo (Transf)' \\
\hline & 73. & Canc_99P & Continuous & $\begin{array}{l}\text { Number of cancellations ‘Coupure inform-mauvais } \\
\text { payeur' }\end{array}$ \\
\hline & 74. & Canc_991 & Continuous & $\begin{array}{l}\text { Number of cancellations ‘Reprise inform-mauvais } \\
\text { payeur’ }\end{array}$ \\
\hline & 75. & Nbr_canc & Continuous & Number of cancellations (all types) \\
\hline & 76. & No_renew & Continuous & $\begin{array}{l}\text { Number of times that customer renewed his } \\
\text { subscription }\end{array}$ \\
\hline & 77. & Canc_tot & Continuous & Number of total cancellations (csupr ending on ' $\mathrm{T}$ ') \\
\hline
\end{tabular}

\begin{tabular}{|l|l|l|l|}
\hline 78. & Nbr_son & Continuous & Number of questionnaires the customer filled in \\
\hline
\end{tabular}




\begin{tabular}{|c|c|c|c|}
\hline 79. & Rec_son & Continuous & $\begin{array}{l}\text { The number of days that elapsed since filling in } \\
\text { the last questionnaire }\end{array}$ \\
\hline 80. & Son_mv & Continuous & If nbr_son $=0$, son_mv $=1 ;$ else son_mv $=0$. \\
\hline 81. & Eg_2 & Continuous & \multirow{4}{*}{$\begin{array}{l}\text { Number of generic letters of a certain type the } \\
\text { pay-TV company received from a certain } \\
\text { customer. } \\
\qquad \rightarrow 2=\text { entrants, } 6=\text { sondages, } 8=\text { =marketing }\end{array}$} \\
\hline 82. & Eg_6 & Continuous & \\
\hline 83. & Eg_8 & Continuous & \\
\hline 84. & Eg_else & Continuous & \\
\hline 85. & Ep_1 & Continuous & \multirow{4}{*}{$\begin{array}{l}\text { Number of personal letters of a certain type the } \\
\text { pay-TV company received from a certain } \\
\text { customer. } \\
\qquad \begin{array}{l}\rightarrow 1=\text { bons restitution, } 2=\text { entrants, } \\
5=\text { messages cat }\end{array}\end{array}$} \\
\hline 86. & Ep_2 & Continuous & \\
\hline 87. & Ep_5 & Continuous & \\
\hline 88. & Ep_else & Continuous & \\
\hline 89. & Og_3 & Continuous & \multirow{16}{*}{$\begin{array}{l}\text { Number of generic letters of a certain type the } \\
\text { pay-TV company sent to a certain customer. } \\
\rightarrow 3=\text { sortants circul., } 6=\text { =sondages, } \\
7=\text { divers, } 8=\text { =marketing, } 9=\text { =cadeaux autres, } \\
10=\text { cadeaux parrainage } \\
11=\text { cinema, } 13=\text { =évenements, } 14=\text { sports, } \\
15=\text { =jeux concours, } 16=\text { transformation, } \\
19=\text { parrainage offre, } 21=\text { reabo-routeur, } \\
22=\text { =reabo-circulaires, } 25=\text { =sortants } \\
\text { magazine/gazette }\end{array}$} \\
\hline 90. & Og_6 & Continuous & \\
\hline 91. & Og_7 & Continuous & \\
\hline 92. & Og_8 & Continuous & \\
\hline 93. & Og_9 & Continuous & \\
\hline 94. & Og_10 & Continuous & \\
\hline 95. & Og_11 & Continuous & \\
\hline 96. & Og_13 & Continuous & \\
\hline 97. & Og_14 & Continuous & \\
\hline 98. & Og_15 & Continuous & \\
\hline 99. & Og_16 & Continuous & \\
\hline 100. & Og_19 & Continuous & \\
\hline 101. & Og_21 & Continuous & \\
\hline 102. & Og_22 & Continuous & \\
\hline 103. & Og_25 & Continuous & \\
\hline 104. & Og_else & Continuous & \\
\hline 105. & Op & Continuous & $\begin{array}{l}\text { Number of personal letters the pay-TV company } \\
\text { sent to a certain customer. }\end{array}$ \\
\hline 106. & Rec_eg & Continuous & \multirow{4}{*}{$\begin{array}{l}\text { How long ago (on 31/3/2002) did the pay-TV } \\
\text { company receive a letter from a certain customer? }\end{array}$} \\
\hline 107. & Eg_mv & Binary & \\
\hline 108. & Rec_ep & Continuous & \\
\hline 109. & Ep_mv & Binary & \\
\hline 110. & Rec_og & Continuous & \multirow{4}{*}{$\begin{array}{l}\text { How long ago (on 31/3/2002) did the pay-TV } \\
\text { company send a letter to a certain customer? }\end{array}$} \\
\hline 111. & Og_mv & Binary & \\
\hline 112. & Rec_op & Continuous & \\
\hline 113. & Op_mv & Binary & \\
\hline 114. & In_call_A & Continuous & \multirow{10}{*}{$\begin{array}{l}\text { Number of times customer called the pay-TV } \\
\text { company, (relative to length of relationship for } \\
\text { last 3,5 years) concerning: } \\
\text { A - his subscription, C - his contract } \\
\text { D - to ask for additional information , } \\
\text { E - other changes, F - payments } \\
\text { G - call interrupted by subsciber } \\
\text { O - games, gifts, member-gets-member } \\
\text { P - program } \\
\text { R - reabo } \\
\text { T - technical problems }\end{array}$} \\
\hline 115. & In_call_C & Continuous & \\
\hline 116. & In_call_D & Continuous & \\
\hline 117. & In_call_E & Continuous & \\
\hline 118. & In_call_F & Continuous & \\
\hline 119. & In_call_G & Continuous & \\
\hline 120. & In_call_O & Continuous & \\
\hline 121. & In_call_P & Continuous & \\
\hline 122. & In_call_R & Continuous & \\
\hline 123. & In_call_T & Continuous & \\
\hline 124. & Distr_call_C & Continuous & \multirow{4}{*}{$\begin{array}{l}\text { Number of times distributor called concerning } \\
\text { subscriber. (explanation of types as above) }\end{array}$} \\
\hline 125. & Distr_call_D & Continuous & \\
\hline 126. & Distr_call_E & Continuous & \\
\hline 127. & Distr_call_R & Continuous & \\
\hline
\end{tabular}




\begin{tabular}{|c|c|c|c|}
\hline 128. & After_call_C_ & Continuous & \multirow{6}{*}{$\begin{array}{l}\text { "After call work" on the subscriber (types as } \\
\text { above, } \mathrm{X} \text { - else) }\end{array}$} \\
\hline 129. & After_call_E & Continuous & \\
\hline 130. & After_call_F & Continuous & \\
\hline 131. & After_call_R & Continuous & \\
\hline 132. & After_call_T & Continuous & \\
\hline 133. & After_call_X & Continuous & \\
\hline 134. & Inbound_mail & Continuous & Number of inbound mails \\
\hline 135. & Stand_contact & Continuous & Number of contacts between customer and Stand \\
\hline 136. & Outbound_calls_pos & Continuous & Number of positive outbound calls \\
\hline 137. & Outbound_calls_neg & Continuous & Number of negative outbound calls \\
\hline 138. & Rec_inbound_A & Continuous & \multirow{10}{*}{ Recency of the last inbound call of each type } \\
\hline 139. & Rec_inbound_C & Continuous & \\
\hline 140. & Rec_inbound_D & Continuous & \\
\hline 141. & Rec_inbound_E & Continuous & \\
\hline 142. & Rec_inbound_F & Continuous & \\
\hline 143. & Rec_inbound_G & Continuous & \\
\hline 144. & Rec_inbound_O & Continuous & \\
\hline 145. & Rec_inbound_P & Continuous & \\
\hline 146. & Rec_inbound_R & Continuous & \\
\hline 147. & Rec_inbound_T & Continuous & \\
\hline 148. & Rec_inbound_mail & Continuous & Recency of last inbound mail \\
\hline 149. & Rec_stand_contact & Continuous & Recency of last Stand contact \\
\hline 150. & Rec_out_pos & Continuous & Recency of last positive outbound call \\
\hline 151. & Rec_out_neg & Continuous & Recency of last negative outbound call \\
\hline 152. & Rec_inbound_A_mv & Binary & \multirow{14}{*}{ If there was no call of certain type then $=1$, else 0} \\
\hline 153. & Rec_inbound_C_mv & Binary & \\
\hline 154. & Rec_inbound_D_mv & Binary & \\
\hline 155. & Rec_inbound_E_mv & Binary & \\
\hline 156. & Rec_inbound_F_mv & Binary & \\
\hline 157. & Rec_inbound_G_mv & Binary & \\
\hline 158. & Rec_inbound_O_mv & Binary & \\
\hline 159. & Rec_inbound_P_mv & Binary & \\
\hline 160. & Rec_inbound_R_mv & Binary & \\
\hline 161. & Rec_inbound_T_mv & Binary & \\
\hline 162. & Rec_inbound_mail_mv & Binary & \\
\hline 163. & Rec_stand_contact_mv & Binary & \\
\hline 164. & Rec_out_pos_mv & Binary & \\
\hline 165. & Rec_out_neg_mv & Binary & \\
\hline 166. & Call_positive & Continuous & \multirow{2}{*}{ Number of positive and negative inbound calls } \\
\hline 167. & Call_negative & Continuous & \\
\hline 168. & Rec_positive & Continuous & Recency of last positive outbound call \\
\hline 169. & Rec_negative & Continuous & Recency of last negative outbound call \\
\hline 170. & Rec_pos_mv & Continuous & \multirow{2}{*}{ If there was no call of certain type then $=1$, else 0} \\
\hline 171. & Rec_neg_mv & Continuous & \\
\hline
\end{tabular}


Appendix B

Variable importance in commercial churn model

\begin{tabular}{|c|c|c|c|}
\hline \multirow[b]{2}{*}{ Variable Name } & \\
\hline & Z score & $\begin{array}{l}\text { Importance } \\
\text { ranking }\end{array}$ & $\mathbf{p}$ \\
\hline info_mv & 42,518 & 1 & 0 \\
\hline rec_og & 38,233 & 2 & 0 \\
\hline eg_-2 & 38,201 & 3 & 0 \\
\hline length_subs & 31,786 & 4 & 0 \\
\hline lor & 29,396 & 5 & 0 \\
\hline canc_99P & 28,443 & 6 & 0 \\
\hline noc2 2 & 26,218 & 7 & 0 \\
\hline monetary & 25,968 & 8 & 0 \\
\hline rap_amount_c & 24,908 & 9 & 0 \\
\hline nov2 & 23,86 & 10 & 0 \\
\hline rap_amount & 23,471 & 11 & 0 \\
\hline og_3 & 22,042 & 12 & 0 \\
\hline rec_inbound_A & 21,392 & 13 & 0 \\
\hline call_negative- & 20,932 & 14 & 0 \\
\hline cash_free & 20,817 & 15 & 0 \\
\hline rec_positive & 20,488 & 16 & 0 \\
\hline rec_ep & 20,136 & 17 & 0 \\
\hline no_rappels & 19,713 & 18 & 0 \\
\hline in_call_t & 18,865 & 19 & 0 \\
\hline rec_negative & 18,721 & 20 & 0 \\
\hline in_call_A & 17,487 & 21 & 0 \\
\hline no_renew & 17,431 & 22 & 0 \\
\hline markov2 & 17,325 & 23 & 0 \\
\hline in_call_F & 17,32 & 24 & 0 \\
\hline in_call_R & 16,958 & 25 & 0 \\
\hline rec_inbound_R & 16,889 & 26 & 0 \\
\hline no_cycles & 16,237 & 27 & 0 \\
\hline rec_inbound_R_mv & 16,232 & 28 & 0 \\
\hline nbr_canc & 16,232 & 29 & 0 \\
\hline og_19 & 15,981 & 30 & 0 \\
\hline og_22 & 15,803 & 31 & 0 \\
\hline rap_cut_adv & 15,71 & 32 & 0 \\
\hline rec_inbound_F & 15,624 & 33 & 0 \\
\hline canc_991 & 15,286 & 34 & 0 \\
\hline og_8 & 14,62 & 35 & 0 \\
\hline at_ttcmens & 14,306 & 36 & 0 \\
\hline rec_inbound_A_mv & 14,218 & 37 & 0 \\
\hline call_positive & 14,008 & 38 & 0 \\
\hline rec_inbound_D & 13,983 & 39 & 0 \\
\hline exp_month_ $\overline{4}$ & 13,753 & 40 & 0 \\
\hline rap_deactiv & 13,426 & 41 & 0 \\
\hline rec_inbound_T & 13,337 & 42 & 0 \\
\hline rap_rec & 13,197 & 43 & 0 \\
\hline terme & 13,127 & 44 & 0 \\
\hline markov & 13,113 & 45 & 0 \\
\hline rec_inbound_F_mv & 12,918 & 46 & 0 \\
\hline rap_smooth ${ }^{-}-$ & 12,901 & 47 & 0 \\
\hline ep_- 2 & 12,867 & 48 & 0 \\
\hline tel_mob & 12,783 & 49 & 0 \\
\hline tel fix & 12,14 & 50 & 0 \\
\hline
\end{tabular}




\begin{tabular}{|c|c|c|c|}
\hline \multirow[b]{2}{*}{ Variable Name } & \\
\hline & Z score & $\begin{array}{c}\text { Importance } \\
\text { ranking } \\
\end{array}$ & $\mathbf{p}$ \\
\hline ind_subs & 11,926 & 51 & $\overline{0}$ \\
\hline ep_mv & 11,406 & 52 & 0 \\
\hline nov & 11,351 & 53 & 0 \\
\hline in_call_D & 11,221 & 54 & 0 \\
\hline og_16 & 10,95 & 55 & 0 \\
\hline og_6 & 10,897 & 56 & 0 \\
\hline rec_eg & 10,877 & 57 & 0 \\
\hline rec_inbound_D_mv & 9,614 & 58 & 0 \\
\hline rec_neg_mv & 9,586 & 59 & 0 \\
\hline rec_inbound_T_mv & 9,561 & 60 & 0 \\
\hline rec_inbound_E & 9,27 & 61 & 0 \\
\hline rec_inbound_C & 9,255 & 62 & 0 \\
\hline age & 8,959 & 63 & 0 \\
\hline age_mv & 8,833 & 64 & 0 \\
\hline og_mv & 8,633 & 65 & 0 \\
\hline rap_mv & 8,432 & 66 & 0 \\
\hline in_call_c & 8,408 & 67 & 0 \\
\hline ep_5 & 8,322 & 68 & 0 \\
\hline rap_to_pay & 8,199 & 69 & 0 \\
\hline at_duree & 8,161 & 70 & 0 \\
\hline og_11 & 8,077 & 71 & 0 \\
\hline product2 & 8,049 & 72 & 0 \\
\hline noc & 7,993 & 73 & 0 \\
\hline canc_78P & 7,875 & 74 & 0 \\
\hline in_call_E & 7,746 & 75 & 0 \\
\hline no_godchild & 7,735 & 76 & 0 \\
\hline eg_mv & 7,714 & 77 & 0 \\
\hline og_7 & 7,395 & 78 & 0 \\
\hline inbound_mail & 7,089 & 79 & 0 \\
\hline exp_month_1 & 6,974 & 80 & 0 \\
\hline tech & 6,921 & 81 & 0 \\
\hline rec_inbound_E_mv & 6,793 & 82 & 0 \\
\hline rec_inbound_c_mv & 6,764 & 83 & 0 \\
\hline rec_inbound_mail_mv & 6,757 & 84 & 0 \\
\hline rec_pos_mv & 6,718 & 85 & 0 \\
\hline rec_inbound_mail & 6,623 & 86 & 0 \\
\hline rec_stand_contact_mv & 6,547 & 87 & 0 \\
\hline after_call_X & 6,534 & 88 & 0 \\
\hline og_10 & 6,477 & 89 & 0 \\
\hline nbr_int & 6,473 & 90 & 0 \\
\hline after_call_c & 6,413 & 91 & 0 \\
\hline og_14 & 6,34 & 92 & 0 \\
\hline in_call_G & 6,329 & 93 & 0 \\
\hline exp_month_3 & 5,879 & 94 & 0 \\
\hline og_15 & 5,78 & 95 & 0 \\
\hline after_call_R & 5,715 & 96 & 0 \\
\hline domi_monthly & 5,707 & 97 & 0 \\
\hline num_numabo & 5,581 & 98 & 0 \\
\hline parrain & 5,428 & 99 & 0 \\
\hline product1 & 5,384 & 100 & 0 \\
\hline eg_6 & 5,377 & 101 & 0 \\
\hline lc & 5,194 & 102 & 0 \\
\hline eg_8 & 5,091 & 103 & 0 \\
\hline og_25 & 5,051 & 104 & 0 \\
\hline markov_dummy & 4,869 & 105 & 0 \\
\hline exp_month_5 & 4,841 & 106 & 0 \\
\hline after_call_E & 4,638 & 107 & 0 \\
\hline exp_month_2 & 4,456 & 108 & 0 \\
\hline camp_d & 4,429 & 109 & 0 \\
\hline ep_1 & 4,275 & 110 & 0 \\
\hline
\end{tabular}




\begin{tabular}{|c|c|c|c|}
\hline \multirow[b]{2}{*}{ Variable Name } & \\
\hline & Z score & $\begin{array}{c}\text { Importance } \\
\text { ranking }\end{array}$ & $\mathbf{p}$ \\
\hline $\mathrm{op}$ & 4,268 & 111 & $\overline{0}$ \\
\hline opt & 4,257 & 112 & 0 \\
\hline camp_p & 4,066 & 113 & 0 \\
\hline rec_out_pos & 4,027 & 114 & 0 \\
\hline og_21 & 3,841 & 115 & 0 \\
\hline og_13 & 3,812 & 116 & 0 \\
\hline after_call_T & 3,777 & 117 & 0 \\
\hline markov2_dummy & 3,73 & 118 & 0 \\
\hline nbr_products & 3,603 & 119 & 0 \\
\hline after_call_F & 3,465 & 120 & 0 \\
\hline og_else & 3,199 & 121 & 0,001 \\
\hline rec_inbound_O & 3,007 & 122 & 0,001 \\
\hline payeur & 2,929 & 123 & 0,002 \\
\hline in_call_P & 2,902 & 124 & 0,002 \\
\hline canc_tot & 2,873 & 125 & 0,002 \\
\hline distr_call_E & 2,873 & 126 & 0,002 \\
\hline distr_call_C & 2,859 & 127 & 0,002 \\
\hline stand_contact & 2,785 & 128 & 0,003 \\
\hline camp_x & 2,752 & 129 & 0,003 \\
\hline exp_month_8 & 2,447 & 130 & 0,007 \\
\hline exp_month_11 & 2,446 & 131 & 0,007 \\
\hline rap_debt_rec & 2,43 & 132 & 0,008 \\
\hline rec_inbound_G_mv & 2,417 & 133 & 0,008 \\
\hline ccivil $\quad--$ & 2,235 & 134 & 0,013 \\
\hline exp_month_9 & 2,204 & 135 & 0,014 \\
\hline exp_month_6 & 2,195 & 136 & 0,014 \\
\hline eg_else & 2,16 & 137 & 0,015 \\
\hline distr_call_D & 2,146 & 138 & 0,016 \\
\hline op_mv & 2,016 & 139 & 0,022 \\
\hline rap_not_recouvr & 1,87 & 140 & 0,031 \\
\hline prov6 & 1,849 & 141 & 0,032 \\
\hline rec_inbound_O_mv & 1,766 & 142 & 0,039 \\
\hline rec_stand_contact & 1,688 & 143 & 0,046 \\
\hline rec_inbound_G & 1,631 & 144 & 0,051 \\
\hline og_9 & 1,504 & 145 & 0,066 \\
\hline rap_proc_open & 1,502 & 146 & 0,067 \\
\hline distr_call_R & 1,479 & 147 & 0,07 \\
\hline rap_outb- & 1,397 & 148 & 0,081 \\
\hline prov1 & 1,328 & 149 & 0,092 \\
\hline dist_display & 1,321 & 150 & 0,093 \\
\hline rec_out_pos_mv & 1,278 & 151 & 0,101 \\
\hline rec_out_neg_mv & 1,117 & 152 & 0,132 \\
\hline rec_op & 1,073 & 153 & 0,142 \\
\hline business & 1,071 & 154 & 0,142 \\
\hline in_call_o & 0,221 & 155 & 0,413 \\
\hline prov5 & 0,07 & 156 & 0,472 \\
\hline exp_month_10 & $-0,332$ & 157 & 1 \\
\hline outbound_calls_pos & $-0,547$ & 158 & 1 \\
\hline exp_month_7 & $-0,672$ & 159 & 1 \\
\hline nbr_son & $-0,917$ & 160 & 1 \\
\hline rec_out_neg & $-0,929$ & 161 & 1 \\
\hline prov7 & $-0,975$ & 162 & 1 \\
\hline camp_e & $-1,068$ & 163 & 1 \\
\hline rec_inbound_P_mv & $-1,132$ & 164 & 1 \\
\hline rec_inbound_P & $-1,443$ & 165 & 1 \\
\hline outbound_calls_neg & $-1,723$ & 166 & 1 \\
\hline rec_son & $-1,809$ & 167 & 1 \\
\hline prov4 & $-1,971$ & 168 & 1 \\
\hline camp_c & $-2,017$ & 169 & 1 \\
\hline son_mv & $-2,23$ & 170 & 1 \\
\hline ep_êtse & $-2,991$ & 171 & 1 \\
\hline
\end{tabular}




\section{Appendix C \\ Variable importance in commercial churn model}

\begin{tabular}{|c|c|c|c|}
\hline \multirow[b]{2}{*}{ Variable Name } & \\
\hline & Z score & $\begin{array}{l}\text { Importance } \\
\text { ranking }\end{array}$ & $\mathbf{p}$ \\
\hline canc_99P & 52,275 & $\overline{1} 1$ & $\overline{0}$ \\
\hline nbr_canc & 52,046 & 2 & 0 \\
\hline length_subs & 32,944 & 3 & 0 \\
\hline lor & 31,135 & 4 & 0 \\
\hline noc2 & 29,33 & 5 & 0 \\
\hline monetary & 29,294 & 6 & 0 \\
\hline tel_fix & 26,722 & 7 & 0 \\
\hline nov2 & 26,457 & 8 & 0 \\
\hline canc_78P & 25,438 & 9 & 0 \\
\hline rec_ōg & 23,967 & 10 & 0 \\
\hline og_ 3 & 22,054 & 11 & 0 \\
\hline cash_free & 19,613 & 12 & 0 \\
\hline call_positive & 18,406 & 13 & 0 \\
\hline no_renew & 18,277 & 14 & 0 \\
\hline at_ttcmens & 18,228 & 15 & 0 \\
\hline rap̄rec & 17,817 & 16 & 0 \\
\hline in_call_A & 17,525 & 17 & 0 \\
\hline rap_amount_c & 17,212 & 18 & 0 \\
\hline markov2 & 17,149 & 19 & 0 \\
\hline og_19 & 15,868 & 20 & 0 \\
\hline rec_inbound_A & 15,696 & 21 & 0 \\
\hline info-mv $\quad-$ & 15,565 & 22 & 0 \\
\hline og_$\_\overline{8}$ & 15,55 & 23 & 0 \\
\hline rec_negative & 15,305 & 24 & 0 \\
\hline terme & 15,2 & 25 & 0 \\
\hline canc_tot & 14,509 & 26 & 0 \\
\hline rap_smooth & 14,235 & 27 & 0 \\
\hline tel_mob & 14,215 & 28 & 0 \\
\hline in_call_T & 13,972 & 29 & 0 \\
\hline rap_amount & 13,562 & 30 & 0 \\
\hline ind_subs & 13,198 & 31 & 0 \\
\hline rec_positive & 12,723 & 32 & 0 \\
\hline call_negative & 12,349 & 33 & 0 \\
\hline domi_monthly & 12,216 & 34 & 0 \\
\hline rec_inbound_F & 12,103 & 35 & 0 \\
\hline rec_inbound_T & 12,081 & 36 & 0 \\
\hline no_rappels & 12,003 & 37 & 0 \\
\hline age & 11,864 & 38 & 0 \\
\hline markov & 11,25 & 39 & 0 \\
\hline tech & 11,233 & 40 & 0 \\
\hline nov & 11,218 & 41 & 0 \\
\hline canc_991 & 11,158 & 42 & 0 \\
\hline noc & 11,129 & 43 & 0 \\
\hline in_call_c & 11,071 & 44 & 0 \\
\hline rap_cut_adv & 10,692 & 45 & 0 \\
\hline rec_ep & 10,671 & 46 & 0 \\
\hline no_cycles & 10,044 & 47 & 0 \\
\hline rec_inbound_c & 9,829 & 48 & 0 \\
\hline rec_inbound_E & 9,734 & 49 & 0 \\
\hline eg_- & 9,709 & 50 & 0 \\
\hline
\end{tabular}




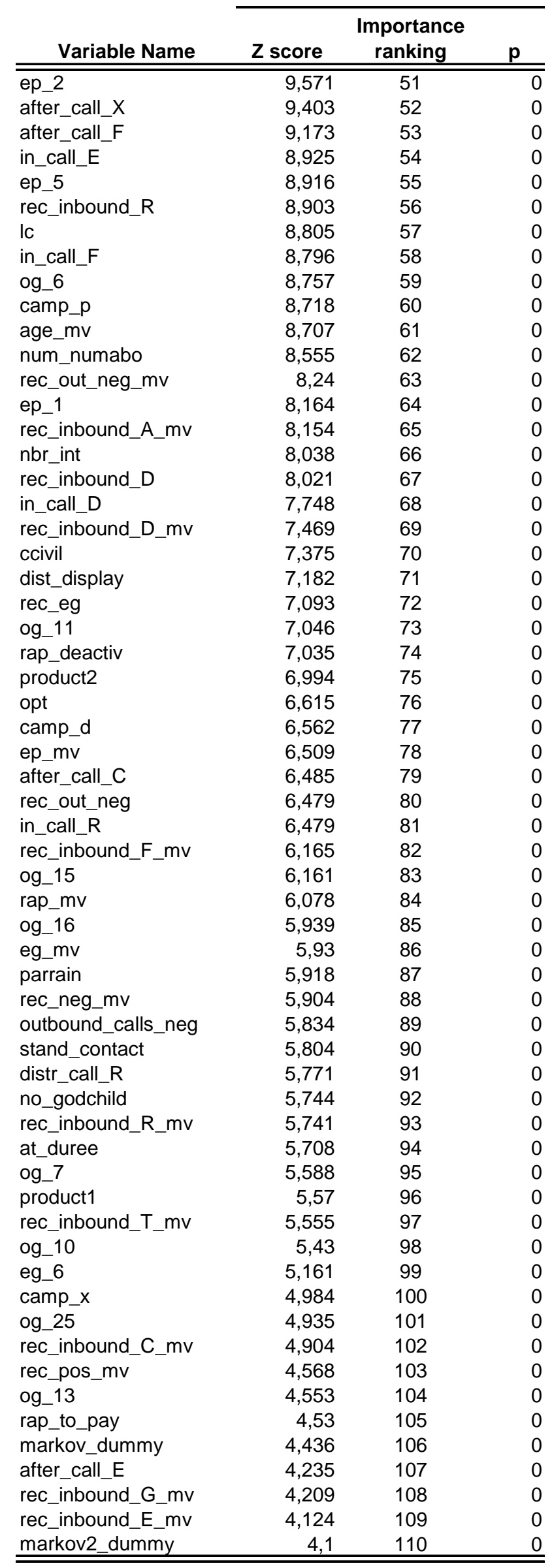




\begin{tabular}{|c|c|c|c|}
\hline \multirow[b]{2}{*}{ Variable Name } & \\
\hline & Z score & $\begin{array}{c}\text { Importance } \\
\text { ranking }\end{array}$ & $\mathbf{p}$ \\
\hline distr_call_D & 4,069 & 111 & $\overline{0}$ \\
\hline eg_else & 4,023 & 112 & 0 \\
\hline exp_month_4 & 3,99 & 113 & 0 \\
\hline exp_month_3 & 3,932 & 114 & 0 \\
\hline rec_stand_contact & 3,765 & 115 & 0 \\
\hline rec_out_pos & 3,623 & 116 & 0 \\
\hline rap_not recouvr & 3,516 & 117 & 0 \\
\hline exp_month_5 & 3,412 & 118 & 0 \\
\hline rap_outb & 3,317 & 119 & 0 \\
\hline exp_month_11 & 3,146 & 120 & 0,001 \\
\hline eg_8 & 3,126 & 121 & 0,001 \\
\hline nbr_products & 2,987 & 122 & 0,001 \\
\hline exp_month_8 & 2,911 & 123 & 0,002 \\
\hline outbound_calls_pos & 2,843 & 124 & 0,002 \\
\hline og_14 & 2,701 & 125 & 0,003 \\
\hline rec_stand_contact_mv & 2,683 & 126 & 0,004 \\
\hline after_call_R & 2,642 & 127 & 0,004 \\
\hline payeur & 2,586 & 128 & 0,005 \\
\hline rec_inbound_G & 2,543 & 129 & 0,005 \\
\hline prov1 & 2,442 & 130 & 0,007 \\
\hline rap_debt_rec & 2,424 & 131 & 0,008 \\
\hline og_9 & 2,389 & 132 & 0,008 \\
\hline exp_month_6 & 2,322 & 133 & 0,01 \\
\hline rec_out_pos_mv & 2,273 & 134 & 0,012 \\
\hline op_mv & 2,007 & 135 & 0,022 \\
\hline og_22 & 1,78 & 136 & 0,038 \\
\hline exp_month_2 & 1,571 & 137 & 0,058 \\
\hline og_mv & 1,51 & 138 & 0,066 \\
\hline rec_inbound_O_mv & 1,47 & 139 & 0,071 \\
\hline exp_month_1 & 1,468 & 140 & 0,071 \\
\hline distr_call_C & 1,431 & 141 & 0,076 \\
\hline rec_son ${ }^{-}$ & 1,328 & 142 & 0,092 \\
\hline prov6 & 1,051 & 143 & 0,147 \\
\hline rap_proc_open & 0,954 & 144 & 0,17 \\
\hline exp_month_9 & 0,903 & 145 & 0,183 \\
\hline rec_op & 0,845 & 146 & 0,199 \\
\hline in_call_G & 0,839 & 147 & 0,201 \\
\hline after_call_t & 0,725 & 148 & 0,234 \\
\hline prov4 & 0,653 & 149 & 0,257 \\
\hline ep_else & 0,599 & 150 & 0,275 \\
\hline son_mv & 0,584 & 151 & 0,28 \\
\hline inbound_mail & 0,504 & 152 & 0,307 \\
\hline distr_call_E & 0,481 & 153 & 0,315 \\
\hline nbr_son & 0,453 & 154 & 0,325 \\
\hline op $^{-}$ & 0,351 & 155 & 0,363 \\
\hline rec_inbound_P & 0,312 & 156 & 0,377 \\
\hline prov5 & 0,101 & 157 & 0,46 \\
\hline in_call_P & $-0,137$ & 158 & 1 \\
\hline business & $-0,339$ & 159 & 1 \\
\hline camp_e & $-0,399$ & 160 & 1 \\
\hline og_21 & $-0,431$ & 161 & 1 \\
\hline exp_month_7 & $-0,447$ & 162 & 1 \\
\hline rec_inbound_mail & $-0,483$ & 163 & 1 \\
\hline in_call_O & $-0,627$ & 164 & 1 \\
\hline rec_inbound_mail_mv & $-0,721$ & 165 & 1 \\
\hline rec_inbound_P_mv & $-0,824$ & 166 & 1 \\
\hline og_else & $-1,096$ & 167 & 1 \\
\hline rec_inbound_O & $-1,244$ & 168 & 1 \\
\hline prov7 & $-1,809$ & 169 & 1 \\
\hline exp_month_10 & $-2,044$ & 170 & 1 \\
\hline camp_c & $-2,989$ & 171 & 1 \\
\hline
\end{tabular}

